\title{
PENGARUH JENIS FILLERTERHADAP NILAI KEKERASAN DAN STRUKTUR MIKRO STAINLESS STEEL AISI 304 PADA PROSES PENGERJAAN LAS TIG
}

\author{
Aldona Dwi Fitriantoํㅜ Rahmat Doni Widodo² \\ 1,2) Jurusan Teknik Mesin, Fakultas Teknik, Universitas Negeri Semarang \\ aldohabibie@students.unnes.ac.id
}

\begin{abstract}
ABSTRAK: Penelitian ini bertujuan untuk mengetahui nilai kekerasan dan struktur mikro hasil lasan sambungan las TIG pada stainless steel AISI 304 dengan penggunaan variasi jenis filler. Metode yang digunakan adalah metode eksperimental untuk membuktikan adanya perbedaan nilai kekerasan dan struktur mikro, yang dihasilkan dari pengelasan TIG dengan memvariasikan penggunaan jenis fillerER 309 $\mathrm{L}$ dan ER $316 \mathrm{~L}$ pada penelitian stainless steel AIS/304. Data hasil penelitian dianalisis secara deskriptif yang ditampilkan dalam bentuk tabel dan grafik. Hasil penelitian membuktikan ada perbedaan nilai kekerasan dan struktur mikro yang dihasilkan oleh variasi filler. Nilai kekerasan maksimal dihasilkan pada penggunaan filler ER $309 \mathrm{~L}$ dengan nilai kekerasan rata-rata $410,32 \mathrm{kgf} / \mathrm{mm} 2$. Nilai kekerasan terendah dihasilkan pada penggunaan filler ER $316 \mathrm{~L}$ dengan nilai kekerasan rata-rata $397,78 \mathrm{kgf} / \mathrm{mm} 2$. Spesimen dengan filler ER $309 \mathrm{~L}$ struktur mikro logam lasan memiliki butiran karbida cr yang kecil mengakibatkan nilai kekerasannya meningkat signifikan dari pada spesimen dengan filler ER $316 \mathrm{~L}$.
\end{abstract}

Kata kunci: las TIG, filler, uji kekerasan, AISI304, dan struktur mikro

\section{PENDAHULUAN}

Stainless steel AISI (American Iron Steel Institue) 304 termasuk baja tahan karat austenitik yang biasa digunakan secara ekstensif dalam dunia industri, seperti industri petrokimia, pembangkit listrik termal, boiler, bejana tekan, alat konstruksi, dan peralatan medis (Susanto dkk, 2012). Pertimbangan pemilihan Stainless steel AISI 304 karena baja jenis ini banyak terdapat atau mudah ditemukan pasaran serta lebih fleksibel ketika dibentuk.

Pengelasan merupakan suatu ikatan metalurgi pada sambungan logam atau logam paduan yang dilaksanakan saat logam dalam keadaan cair. Pada sambungan konstruksi permesinan, terdapat banyak teknik pengelasan.
Karena dengan menggunakan teknik pengelasan sambungan menjadi lebih ringan dan lebih sederhana dalam pembuatannya (Sutowo dan Budiawan, 2008: 46).

Penyambungan stainless steel merupakan salah satu bentuk dari pekerjaan las. Salah satu jenis pengelasan yang digunakan untuk stainless steel dan paduannya yaitu las TIG (Tungsten Inert Gas). jenis pengelasan yang menggunakan panas dari nyala pijar yang terbentuk antara elektroda tungsten yang tidak terumpan dengan menggunakan gas mulia sebagai pelindung terhadap pengaruh luar pada saat proses pengelasan. Elektroda las menggunakan batang wolfram yang dapat menghasilkan 
busur listrik tanpa ikut mencair (Budiyanto dkk, 2017 :54).

Banyak faktor yang mempengaruhi kualitas dari hasil lasan diantaranya: mesin las yang digunakan, bahan yang digunakan, prosedur pengelasan, cara pengelasan, arus pengelasan, jenis sambungan, bahan tambah (filler) dan juru las. Salah satu penyebab diantaranya adalah penggunaan variasi jenis filler sebagai pengisi lasan. Permasalahan tersebut memunculkan beberapa rumusan masalah yaitu pengaruh penggunaan jenis filler ER $309 \mathrm{~L}$ dan ER $316 \mathrm{~L}$ terhadap nilai kekerasan dan struktur mikro.

Salah satu produk $A I S I$ adalah stainless steel 304 atau yang disebut AISI 304. Tipe ini mengandung bahan antara lain seperti pada tabel di bawah.

Tabel 1. Komposisi AISI 304

\begin{tabular}{|c|c|}
\hline Unsur & Prosen Berat (\%) \\
\hline $\mathrm{Fe}$ & 70,40 \\
\hline $\mathrm{Cr}$ & 18,70 \\
\hline $\mathrm{Ni}$ & 8,11 \\
\hline $\mathrm{Mn}$ & 1,06 \\
\hline $\mathrm{Cu}$ & 0,45 \\
\hline $\mathrm{Si}$ & 0,36 \\
\hline $\mathrm{Mo}$ & 0,21 \\
\hline $\mathrm{N}$ & 0,20 \\
\hline $\mathrm{Co}$ & 0,14 \\
\hline $\mathrm{V}$ & 0,09 \\
\hline $\mathrm{P}$ & 0,06 \\
\hline $\mathrm{S}$ & 0,04 \\
\hline $\mathrm{W}$ & 0,04 \\
\hline $\mathrm{C}$ & 0,02 \\
\hline $\mathrm{Sa}$ & 0,02 \\
\hline $\mathrm{Pb}$ & 0,01 \\
\hline $\mathrm{Ca}$ & 0,01 \\
\hline $\mathrm{Ti}$ & 0,01 \\
\hline
\end{tabular}

Menurut Mohruni dan Kembaren (2013) dalam penelitian yang berjudul pengaruh variasi kecepatan dan kuat arus terhadap kekerasan, Kekuatan tarik, struktur mikro baja karbon disimpulkan bahwa VHN rata-rata tertinggi terjadi pada pengelasan dengan kuat arus 80 A dengan kecepatan pengelasan $0,35 \mathrm{~cm} /$ detik dengan kuat arus $100 \mathrm{~A}$ dengan kecepatan pengelasan 0,37 cm/detik. Sementara pada uji tarik Kekuatan tarik tertinggi terdapat pada spesimen dilas dengan kuat arus 80 A dan kecepatan $0,15 \mathrm{~cm} /$ detik.

Berdasarkan hasil ini dapat dilihat besar kuat arus dan kecepatan pengelasan berpengaruh pada kekerasan dan Kekuatan tarik. Nilai kekerasan akan cenderung semakin tinggi jika besar kuat. Tujuan dari penelitian ini adalah mengetahui struktur mikro hasil lasan dan mengetahui nilai kekerasan sambungan las TIG pada stainless steel AISI 304 yang diakibatkan oleh penggunaan variasi dari jenis filler.

\section{METODE}

Metode penelitian adalah suatu cara ilmiah untuk mendapatkan data dengan tujuan dan kegunaan tertentu. Metode penelitian yang digunakan dalam penelitian ini adalah penelitian eksperimental. Metode penelitian eksperimen diartikan sebagai metode penelitian yang digunakan untuk mencari pengaruh perlakuan tertentu terhadap yang lain dalam kondisi yang terkendali (Sugiyono, 2015: 107).

Bahan penelitian berupa plat stainless steel AISI 304 dengan ketebalan $7 \mathrm{~mm}$ dengan variasi jenis filler, yaitu: ER 309 $L$ dan ER $316 L$ dengan menggunakan kampuh $\mathrm{V}$ tunggal $60^{\circ}$. Jarak antar dua plat $1 \mathrm{~mm}$ dan tinggi permukaan akar sebesar 1,5 mm. Bentuk spesimen yang dilas berukuran panjang $80 \mathrm{~mm}$ dan lebar $20 \mathrm{~mm}$. Pembuatan spesimen uji vickers sesuai dengan standar ASTM E92 dengan dimensi seperti yang terlihat pada Gambar 2.

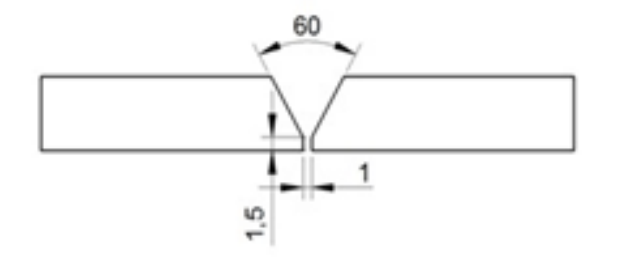

Gambar 1. Kampuh V $60^{\circ}$ 


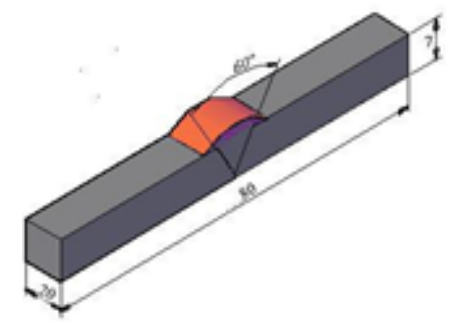

Gambar 2. Spesimen penelitian

\section{HASIL DAN PEMBAHASAN}

Pengaruh penggunaan variasi ER 309 $L$ dan ER 316 L terhadap nilai kekerasan

Berdasarkan hasil pengujian kekerasan dengan mesin uji Vickers merek Future Tech hasil las dengan variasi filler ER 309 L dan ER 316 L diperoleh nilai kekerasan sebagai berikut:

Table 2. Nilai kekerasan dengan fillerER $309 \mathrm{~L}$.

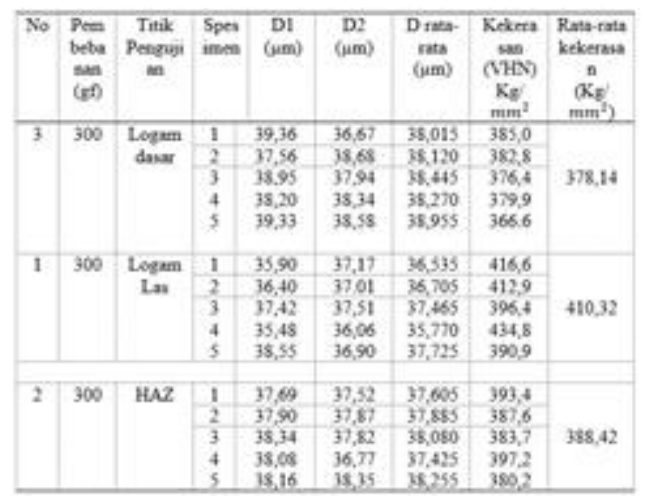

Tabel 3. Nilai kekerasan dengan fillerER $316 \mathrm{~L}$

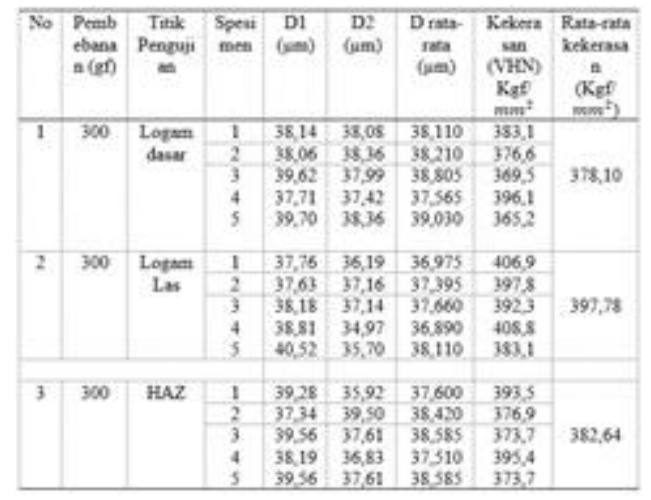

Berdasarkan Tabel 2 dan 3 menunjukkan bahwa adanya perbedaan tingkat kekerasan daerah logam dasar,
HAZ dan logam las yang disebabkan oleh siklus termal yang terjadi pada saat proses pengelasan. Nilai kekerasan pada filler ER $309 \mathrm{~L}$ dan ER $316 \mathrm{~L}$ logam dasar sebesar $378,14 \mathrm{kgf} / \mathrm{mm}^{2}$ dan $378,10 \mathrm{kgf} / \mathrm{mm}^{2}$, sedangkan nilai kekerasan spesimen pada HAZ mengalami kenaikan menjadi 388,42 $\mathrm{kgf} / \mathrm{mm}^{2}$ dan $382,64 \mathrm{kgf} / \mathrm{mm}^{2}$. Nilai kekerasan tertinggi terdapat pada spesimen logam las, karena proses pengelasan TIG menggunakan bahan tambah las (filler). Sebesar 410,32 $\mathrm{kgf} / \mathrm{mm} 2$ dan $397,78 \mathrm{kgf} / \mathrm{mm}^{2}$. Hal ini menunjukkan bahwa pada setiap variasi jenis filler mempunyai nilai kekerasan berbeda- beda seperti ditunjukkan pada grafik berikut.

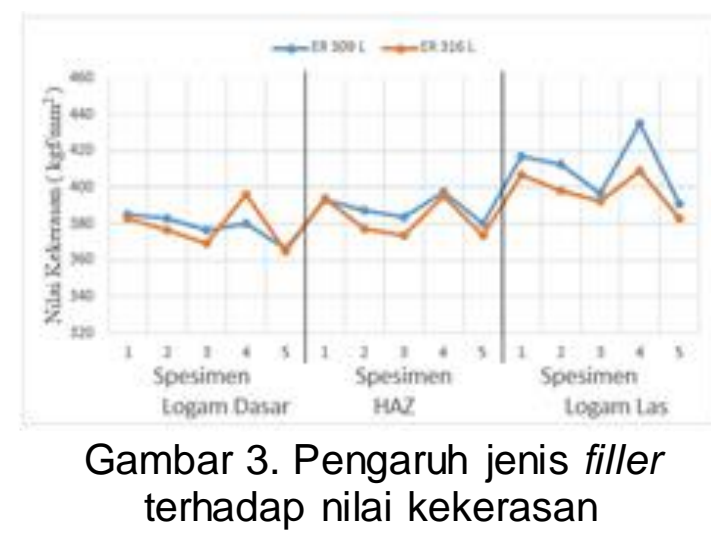

Nilai kekerasan vickers kelompok spesimen logam dasar memiliki nilai kekerasan paling rendah diantara logam las dan HAZ, dengan nilai terkecil pada spesimen 5 filler ER $316 \mathrm{~L}$ sebesar $365,2 \mathrm{kgf} / \mathrm{mm}^{2}$. Sedangkan kelompok logam las memiliki nilai kekerasan paling tinggi, dengan nilai tertinggi pada spesimen 4 filler ER $309 \mathrm{~L}$ sebesar $434,8 \mathrm{kgf} / \mathrm{mm}^{2}$. Dan kelompok HAZ memiliki nilai kekerasan diantara logam dasar dan logam las, dengan nilai tertinggi pada spesimen 4 ER $309 \mathrm{~L}$ sebesar $397,2 \mathrm{kgf} / \mathrm{mm}^{2}$.

Pengaruh penggunaan variasi jenis filler ER $309 L$ dan ER $316 L$ terhadap struktur mikro 
Struktur mikro stainles steel AISI 304 setelah dilakukan pengelasan dengan memvariasikan jenis filler atau logam pengisi dapat kita lihat dengan menggunakan alat berupa mikroskop INFINITY 2 LUMENERA yang terdapat di laboratorium uji Teknik Mesin Universitas Negeri Semarang. Hasil pengamatan berupa gambar struktur yaitu antara lain logam induk, $H A Z$ dan logam las. Berikut merupakan hasil pengamatan struktur mikro:

1. FillerER $309 \mathrm{~L}$

Berikut merupakan struktur mikro hasil pengelasan dengan jenis filler ER $309 \mathrm{~L}$ pada las TIG stainless steel AISI 304.

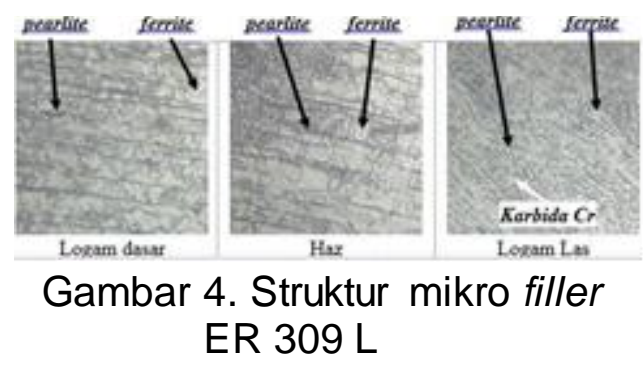

2. Filler ER $316 \mathrm{~L}$

Berikut merupakan struktur mikro hasil pengelasan dengan jenis filler ER $316 \mathrm{~L}$ pada las TIG stainless steel AISI 304.

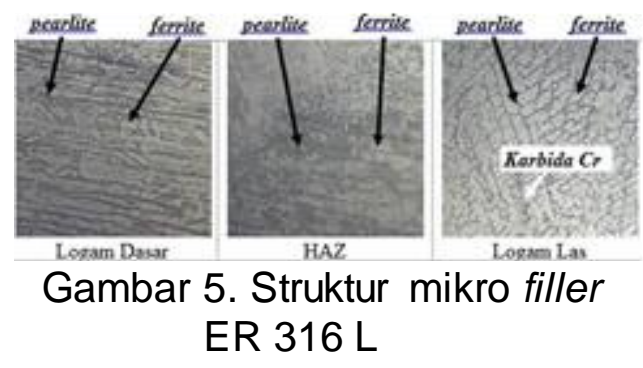

Hasil pengujian struktur mikro pada stainless steel AISI 304 dapat dilihat struktur mikro daerah $H A Z$ dan logam las menunjukkan adanya perbedaan yang terjadi akibat metode las dengan memvariasikan jenis filler. Struktur mikro daerah $H A Z$ hanya mengalami pertumbuhan butir tidak terjadi perubahan unsur. Pertumbuhan butir yang mengalami pengasaran atau pembesaran berpengaruh terhadap tingkat keuletannya. Semakin kasar butiran tersebut menunjukkan tingkat keuletannya menurun. Sedangkan untuk logam las terjadi perubahan struktur. Struktur yang terbentuk pada logam las dengan filler ER $309 \mathrm{~L}$ yaitu berbentuk karbida $\mathrm{cr}$ dengan butian yang lebih kasar dan kecil, ini merupakan struktur yang mempunyai sifat sangat keras dan tangguh akan tetapi mempunyai keuletan yang rendah.

\section{SIMPULAN}

Berdasarkan hasil penelitian dan analisa maka dapat di peroleh kesimpulan sebagai berikut:

1. Variasi jenis filler ER $309 \mathrm{~L}$ dan ER $316 \mathrm{~L}$ berpengaruh terhadap nilai kekerasan Vickers hasil pengelasan TIG stainless steel AISI 304, dimana filler ER $309 \mathrm{~L}$ rata-rata sebesar 410,32 $\mathrm{VHN}$ dengan komposisi kimia $22 \% \mathrm{Cr}$ dan $12 \%$ Ni lebih tinggi dibanding penggunaan filler ER $316 \mathrm{~L}$ ratarata sebesar 397,78 VHN dengan $18 \%$ Cr dan $8 \% \mathrm{Ni}$.

2. Variasi jenis filler ER $309 \mathrm{~L}$ dan ER $316 \mathrm{~L}$ berpengaruh terhadap struktur mikro hasil pengelasan TIG stainless steel AISI 304, dimana filler ER 309 L struktur mikro logam las memiliki butiran karbida $\mathrm{cr}$ lebih kecil dibanding penggunaan filler ER $316 \mathrm{~L}$.

\section{DAFTAR PUSTAKA}

Budiyanto, E., E. Nugroho, dan A. Masruri. 2017. Pengaruh Diameter Filler dan Arus Pada Pengelasan TIG Terhadap Kekuatan Tarik Dan Struktur Mikro Pada Baja Karbon Rendah. Turbo 6(1): 54-61.

Mohruni, A. S. dan B. H. Kembaren. 2013. Pengaruh Variasi Kecepatan dan Kuat Arus terhadap Kekerasan, 
Tegangan Tarik, Struktur Mikro Baja Karbon Rendah dengan Elektroda E 6013. Jurnal Rekayasa Mesin 13(1): 1-8.

Sugiyono. 2015. Metode Penelitian Pendidikan Pendekatan Kuantitatif, Kualitatif, dan R\&D. Bandung: CV. Alfabeta.

Susanto, Ridha, dan M. Huzni, S. 2012. Perilaku Lelah Baja Tahan Karat AISI 304 dalam Lingkungan Korosif. Jurnal Teknik Mesin Pascasarjana Universitas Syiah Kuala 1(1): 1-10.

Sutowo, C. dan I. Budiawan. 2008. Analisa Pengaruh Pengelasan TIG Dan Mig Pada Sambungan Las Dengan Material Tipe SS 316 Dan SS 304. Jurnal Mesin Teknologi 2(1): 4657. 